\title{
A County-level Analysis of the Spatial Distribution of Forest Resources in China
}

\author{
Yuejun Zheng ${ }^{* 1}$, Xiangming Xiao ${ }^{* 2}$, Zhongwei Guo ${ }^{* 3}$ and Theodore E. Howard*4
}

\begin{abstract}
We compared the estimates of forest areas in China from the forest census database (1989-1993) and the land cover database based on remote sensing data of the NOAA AVHRR-derived monthly NDVI composite data from April 1992 to March 1993 at 1-km resolution, and analyzed the spatial distribution of forest resources. According to the land cover database, China has a total forest area of 1.27 million $\mathrm{km}^{2}$, about $3 \%$ lower than the estimate from the forest census database. Our county-level quantitative analysis of forest area and population in China characterized the scarcity and uneven spatial distributions of forest resources per capita in China. On the average, forest area per capita in China is less than one-fifth of the global average of 0.64 ha. Forest area per capita in North, Central, and South China is substantially lower than the national average of $0.11 \mathrm{ha}$, and the spatial distribution in Northeast, Central, and Southwest China is relatively uneven. This study also highlights the challenges for using forest resources to improve the ecological environment, to raise people's living standards, and to spur economic growth in China. Based on analytical results, we proposed three perspectives concerning China's forest resource management in the 21 st century.
\end{abstract}

Keyword:forest resource management, land cover classification, land use/land cover, NDVI data, China

\section{INTRODUCTION}

The ecological and economic importance of forest resources in China is determined by their scarcity. Forests cover only about $13.92 \%$ of China's territory, less than half of the average world forest coverage of $34 \%$. The forest volume per capita in China is only one-eighth of the global average (Ministry of Forestry, 1996a, b, c). Forests are valued for their provision of raw materials for industry and their critical role in soil and water conservation for China's agricultural sectors.

${ }^{* 1}$ The Institute of Statistical Mathematics, 4-6-7 Minami-Azabu, Minato-Ku, Tokyo, Japan, zheng@ism.ac.jp

${ }^{* 2}$ Complex Systems Research Center, Institute for the Study of Earth, Oceans and Space, University of New Hampshire, Durham, New Hampshire, USA, xiangming.xiao@unh.edu

${ }^{* 3}$ The Institute of Zoology, Chinese Academy of Sciences, Beijing, China.

${ }^{*}$ Department of Natural Resources, University of New Hampshire, Durham, New Hamp-shire, USA, tehoward@christa.unh.edu
With a severely limited amount of arable land, farmland requires the environmental services provided by forests to protect agricultural productivity (HuANG and Scotr, 1995). In Northeastern, Southern and Southwestern forest regions, it has been estimated that the annual added value of water and soil conservation, air purification, acid rain buffering and other functions was 2-10 times the gross output value of timber, wood processing, and orchard production (Kong et al., 1996). Forests also provide $40 \%$ of the fuel for rural households (MINISTRY OF ForEstry, 1995). For this reason, Richardson calls China the most forest-dependent civilization in the world (RICHARDSON, 1990). In addition to being the world's most populous country, China has a rapidly growing economy, and the combination of these two factors has increased pressure on its natural resources.

Although the voluminous writings on China's forest resources and forest land-use have stressed the national or provincial-level aggregate changes (Li, 1998; HarknEss, 1998; AlBers et al., 1998), few studies have dealt with the county-level forest distribution. In this study, we organized four spatial data sets for China: (1) the China Land Cover Characteristics Database, which is part of the global 1-km land cover mapping effort under the guidance of the International GeosphereBiosphere Program (Loveland and Belware, 1997); (2) the 
1:1,000,000 map of county-level administration boundaries for China; (3) the 1990 census data of population and agriculture statistics; and (4) the Chinese National Forest Resources Census data for the period 1988-1993. We examined the spatial distribution patterns of forest types, forest areas, and percentage forest cover, as well as forest area per capita at the county level. Our objective was to analyze forest distribution in relation to population distribution at the county level. Our study provides detailed information on the spatial characteristics of forest resources in China, and reveals important information for guiding forest resource management in the 21 st century.

\section{DESCRIPTION OF SPATIAL DATA SETS}

1. China land cover characteristics database :

We used the China Land Cover Characteristics Database that was developed at the U.S. Geological Survey Earth Resources Observation Systems (EROS) Data Center in cooperation with the Chinese Academy of Surveying and Mapping (YANG et al., 1997; ZHI-LAANG ZHU, personal communication). The classification of Seasonal Land Cover Regions (SLCR) was based on monthly Normalized Difference Vegetation Index (NDVI) composite data at $1-\mathrm{km}$ resolution over the period of April 1992 to March 1993 from 1-km resolution National Oceanic and Atmosphere Administration (NOAA) Advanced Very High Resolution Radiometer (AVHRR). The 153 distinct spectral classes were mapped into 118 land cover classes. The first 31 land cover classes characterized various types of forests, and were integrated into five forest types based on the International GeosphereBiosphere Programme (IGBP) Global Land Cover Classification System (RunNing et al., 1994; Belware and Loveland, 1995). Forests are identified as lands dominated by trees with a percentage canopy cover greater than $60 \%$ and height exceeding 2 meters. The five forest types are identified as follows:

(1) Evergreen Needleleaf Forests: Dominated by needleleaf tree communities in which almost all trees remain green all year. Canopy is never without green foliage.

(2) Evergreen Broadleaf Forests: Dominated by broadleaf tree communities in which almost all trees remain green all year. Canopy is never without green foliage.

(3) Deciduous Needleleaf Forest: Consist of seasonal needleleaf tree communities with an annual cycle of leafon and leaf-off periods.

(4) Deciduous Broadleaf Forests: Consist of seasonal broadleaf tree communities with an annual cycle of leafon and leaf-off periods.

(5) Mixed Forests: Consist of tree communities with interspersed mixtures or mosaics of the other four forest cover types. None of the forest types exceeds $60 \%$ of landscape.

The SLCR database also includes a category of cropland/natural vegetation mosaic (e.g. tea, rubber, bamboo, eucalyptus and oil palm), representing lands with a mosaic of croplands, forests, shrublands, and grasslands in which no single component comprises more than $60 \%$ of the landscape. We excluded this category from our analysis, because we can not quantify the proportions of forest and other vegetation types within a $1-\mathrm{km}$ resolution gridcell.

\section{The $1: 1,000,000$ scale map of administrative boundaries of} China :

We used the 1:1,000,000 scale maps of administrative boundaries of China for our geographical analysis, which represents China's national provincial, regional and county administrative boundaries as of 31 December 1990 (CIESIN, 1998). The ARC/INFO (v.7.1.1) GIS package was used in data analysis. The original digital map is in the Lambert conformal conic projection. As the above SLCR database used the Lambert Azimuth projection, we re-projected the county boundary coverage from the Lambert conformal conic projection to the Lambert Azimuth projection. We then gridded the polygon county coverage into meshes at $1-\mathrm{km}$ resolution. We overlaid the gridded county boundary map onto the SLCR land cover map and counted pixels for each land cover class within each county boundary. Thus, a county-SLCR matrix was obtained. According to the National Economic Atlas of China, at the end of 1990, China had 2,833 county-level units (IGCAS, 1994).

\section{The population census data for 1990 :}

We used the population census and agricultural statistics database of China for 1990 (PCAC90, CIESIN, 1998). This database reported variables for only 2,438 county-level units in mainland China, since some units with small area were merged in the process of gridding (CIESIN, 1998). However, the above administrative boundary map (CIESIN 1998) has 2,875 polygons representing 2,439 county-level units in mainland China. Although the number of counties in the PCAS90 and the SLCR databases differed in number by only one $(2,438$ versus 2,439 ), in reality there are much more profound differences. We reviewed the units in each database and generated a consistent set of 2,375 county-level administrative units to use in subsequent analysis. However, we calculated the forest area per capita only for 2,366 counties because there are still 9 counties short of corresponding population data.

\section{The forestry census database at provincial-level :}

We used the Chinese National Forest Resource Census data set for the period of 1989-1993 (MINISTRY OF FORESTRY, 1996b; NFRC93). The forest area estimates in the NFRC93 were inferred statistically from the fourth Continuous Forest Inventory (CFI) through repeatedly measuring the permanent plots using ground inventories and remote sensing techniques. These permanent plots cover almost all land types (except deserts and grasslands) in mainland China at a 4 or $8-\mathrm{km}$ 
resolution grid and are normally re-measured every five years. The Chinese Ministry of Forestry published the NFRC93 data at the provincial level, and we used this provincial level NFRC93 data in this study to compare with forest areas derived from the SLCR database.

\section{RESULTS}

A Comparison of Provincial Level Forest Area Estimates from the NFRC93 and the SLCR Data Sets

We first compared the total forestland areas from the SLCR and the NFRC93 by using the provincial level values of both. Fig. 1 shows that the forest area estimates from the SLCR are highly correlated with those from the NFRC93 at provincial level $\left(r^{2}=0.76\right)$. The total forest area estimate from the SLCR is about 3\% lower than that from the NFRC93. However, at the provincial level, total forest areas from the SLCR are greater than the NFRC93 in 10 provincial units mainly in Northeast, Southwest, and Northwest China, while in the other 20 provinces almost all located in North, Central, and South China, total forest areas from the NFRC93 are larger than the SLCR data set (Table 1). In particular, there are remarkable differences between the two databases for Tianjin, Shandong, Henan, Shanghai, Jiangsu, Guizhou and Qinghai, but discussing those problems related to the accuracy of the two databases is beyond the scope of this paper. Consequently, all results in the subsequent sections are based on the forestland area from the China Land Cover Characteristics Database.
National-scale Analysis of Forest Areas and Population

For national scale analysis we considered the 2,375 counties in China and five forest types derived from the SLCR database. According to the SLCR database, China has approximately 1.27 million $\mathrm{km}^{2}$ of forests (Table 2). The percentage forest cover for China is about $13.48 \%$, which is 0.44\% lower than the NFRC93 statistical results. Of the $13.48 \%$ forest coverage in China, the fractions of evergreen needleleaf forests, evergreen broadleaf forests, deciduous needleleaf forests, deciduous broadleaf forests, and mixed forests are $3.08 \%, 0.64 \%, 1.15 \%, 2.04 \%$ and $6.58 \%$ of total land area, respectively.

About $43 \%$ of 2,375 counties have a percentage forest cover lower than $1 \%$ over the total land area of the county (Fig. 2). Almost all (95\%) of these counties are located in North, Central, Southwest and Northwest China. Moreover, about $69 \%$ of 2,375 counties have a percentage forest cover lower than the national average of $13.48 \%$. Of 2,375 counties in China, only 400 counties have a percentage forest cover higher than the world-averaged forest coverage of 34\% (Ministry of Forestry 1996c; also see Fig. 2), and $76 \%$ of these counties are located in Northeast, Central and Southwest China (Table 2). The skewed distribution in Fig. 2 illustrates the low forest coverage and uneven spatial distribution of forest resources in China.

We also calculated forest area per capita at the national scale, using the county-level SLCR area estimates and the 1990 China's county-level population census data (CIESIN, 1998). The forest area per capita in China is approximately 0.11

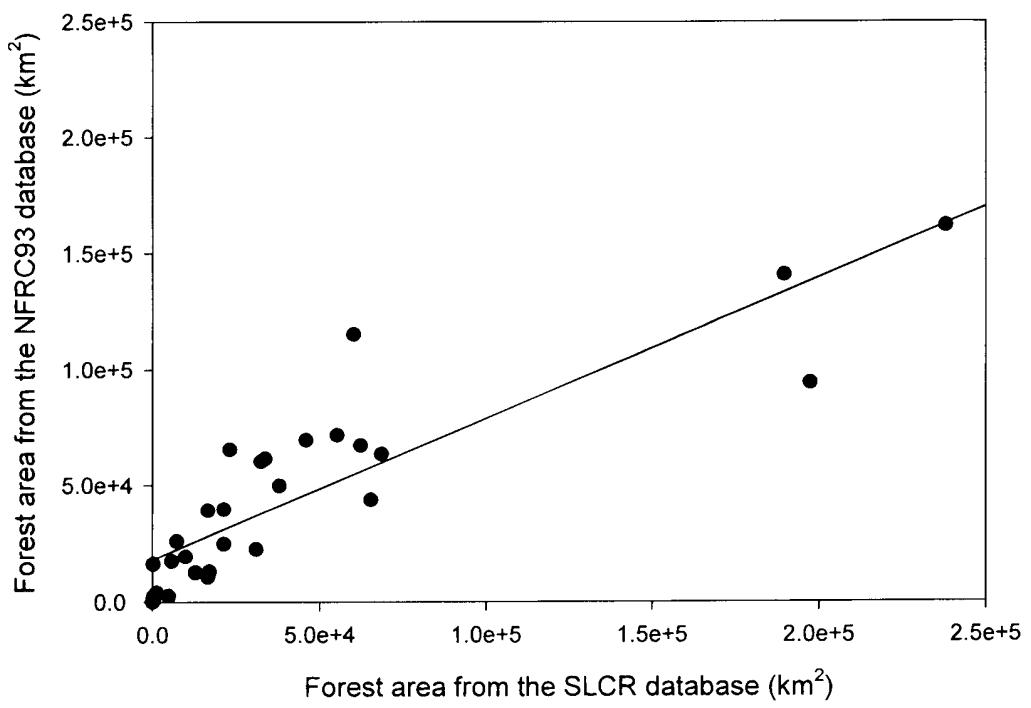

Fig. 1 The SLCR versus NFRC93 estimates of provincial-level forestland area $\left(\mathrm{km}^{2}\right)$ in 30 mainland provinces.

The SLCR area is based on the aggregate pixels classified as forestland in all provinces, while the NFRC93 area is a total of all forestland area. The correlation between natural logarithms of forestland area estimates from SLCR and NFRC93 is $\mathbf{r}^{2}=0.76$. 
Table 1 Forestland areas $\left(\mathrm{km}^{2}\right)$ in China by provinces from National Forest

Resource Census(89-93) (NFRC93) and from 1992-1993 NOVA AVHRR spectrums(SCLR)

\begin{tabular}{|c|c|c|c|c|c|}
\hline \multirow{2}{*}{ Province \& region } & \multicolumn{2}{|c|}{ Forestland area } & \multicolumn{2}{|c|}{ Forest coverage } & \multirow{2}{*}{$\begin{array}{r}\text { Forestland area } \\
\text { per capita }\end{array}$} \\
\hline & NFRC93 & SLCR & NFRC93 & SLCR & \\
\hline Total China & $1,317,330$ & $1,274,283$ & 13.77 & 13.48 & $\overline{0.11}$ \\
\hline Noth China & 74,850 & 44,889 & 10.83 & 6.49 & 0.02 \\
\hline Beijing & 2,671 & 4,801 & 14.99 & 28.91 & 0.04 \\
\hline Tianjin & 858 & 67 & 7.47 & 0.57 & 0.00 \\
\hline Hebei & 24,806 & 21,323 & 13.35 & 11.37 & 0.03 \\
\hline Shanxi & 12,700 & 12,800 & 8.11 & 8.17 & 0.04 \\
\hline Shandong & 16,288 & 193 & 10.7 & 0.13 & 0.00 \\
\hline Henan & 17,527 & 5,705 & 10.5 & 3.45 & 0.01 \\
\hline Northeast China & 264,275 & 323,094 & 33.49 & 41.02 & 0.33 \\
\hline Liaoning & 39,186 & 16,584 & 26.89 & 11.37 & 0.04 \\
\hline Jilin & 63,469 & 68,598 & 33.6 & 35.93 & 0.28 \\
\hline Heilongjiang & 161,620 & 237,912 & 35.55 & 52.75 & 0.68 \\
\hline Cnetral China & 246,878 & 227,146 & 27.04 & 24.81 & 0.07 \\
\hline Shanghai & 147 & 2 & 2.47 & 0.03 & 0.00 \\
\hline Jiangsu & 4,122 & 1,224 & 4.02 & 1.21 & 0.00 \\
\hline Zhejiang & 43,759 & 65,375 & 42.99 & 64.07 & 0.16 \\
\hline Anhui & 22,561 & 31,035 & 16.33 & 22.13 & 0.06 \\
\hline Jiangxi & 67,277 & 62,259 & 40.35 & 37.14 & 0.17 \\
\hline Hubei & 39,522 & 21,341 & 21.26 & 11.47 & 0.04 \\
\hline Hunan & 69,490 & 45,910 & 32.8 & 21.66 & 0.08 \\
\hline South China & 197,795 & 105,940 & 34.63 & 18.59 & 0.07 \\
\hline Fujian & 61,484 & 33,737 & 50.6 & 27.72 & 0.11 \\
\hline Guangdong & 65,431 & 23,125 & 36.78 & 13.03 & 0.04 \\
\hline Guangxi & 60,217 & 32,495 & 25.34 & 13.75 & 0.08 \\
\hline Hainan & 10,663 & 16,583 & 31.27 & 48.2 & 0.27 \\
\hline Southwest China & 235,388 & 264,762 & 20.92 & 23.48 & 0.15 \\
\hline Sichun & 115,318 & 60,152 & 20.37 & 10.61 & 0.06 \\
\hline Guizhou & 26,028 & 7,202 & 14.75 & 4.09 & 0.02 \\
\hline Yunnan & 94,042 & 197,408 & 24.58 & 51.37 & 0.53 \\
\hline Northwest China & 298,144 & 310,337 & 6.9 & 7.36 & 0.30 \\
\hline Inner Mongolia & 140,657 & 189,603 & 12.14 & 16.52 & 0.88 \\
\hline Tibet & 71,689 & 55,246 & 5.84 & 4.59 & 2.52 \\
\hline Shaanxi & 49,735 & 37,972 & 24.15 & 18.44 & 0.11 \\
\hline Gansu & 19,486 & 9,875 & 4.33 & 2.44 & 0.03 \\
\hline Qinghai & 2,501 & 262 & 0.35 & 0.04 & 0.00 \\
\hline Ningxia & 1,020 & 375 & 1.54 & 0.73 & 0.01 \\
\hline Xinjiang & 13,056 & 17,004 & 0.79 & 1.04 & 0.11 \\
\hline
\end{tabular}

*Note: NFRC93= National Forest Resource Census (1989-1993)

SLCR= Seasonal Land Cover Regions (1992-1993)

hectare (ha) (Table 2). Approximately $74 \%$ of the 2,366 counties with population census data in 1990 have a forest area per capita less than the national average of 0.11 ha (Fig. 3). Only 195 counties in China have forest area per capita exceeding the world average of 0.64 ha (Ministry of Forestry, 1996c; also see Fig. 3). At the provincial level, the forest area per capita in 19 provinces was less than 0.11 ha. Tibet has the highest value of 2.52 ha per capita of all 30 provinces because of its low population density.
Regional-scale Analysis of Forest Areas and Population

The 30 provincial units in mainland China are often grouped into 6 administrative regions with different natural, social and economic conditions: North, Northeast, Central, South, Southwest, and Northwest China (Table 1). In this section we assessed the forest areas, percentage forest cover by vegetation type, and frequency distribution of counties by percentage forest cover and forest area per capita for each of 


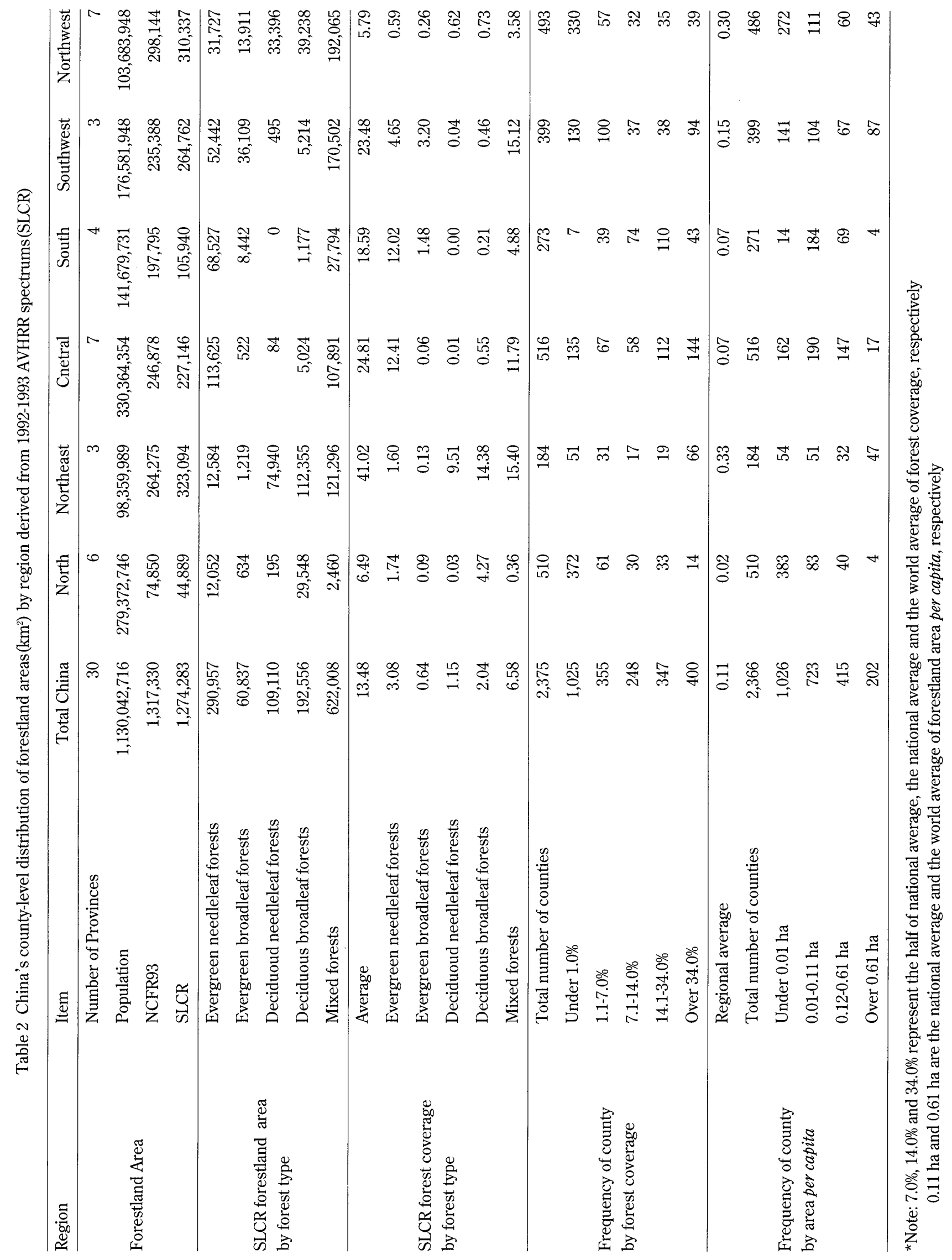




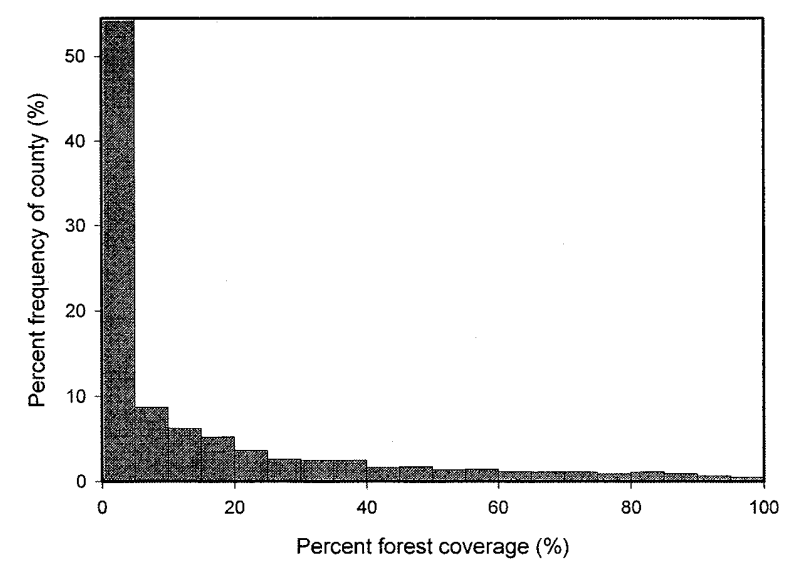

Fig. 2 National frequency distribution by county based on the county-level forest coverage estimated from the SLCR database

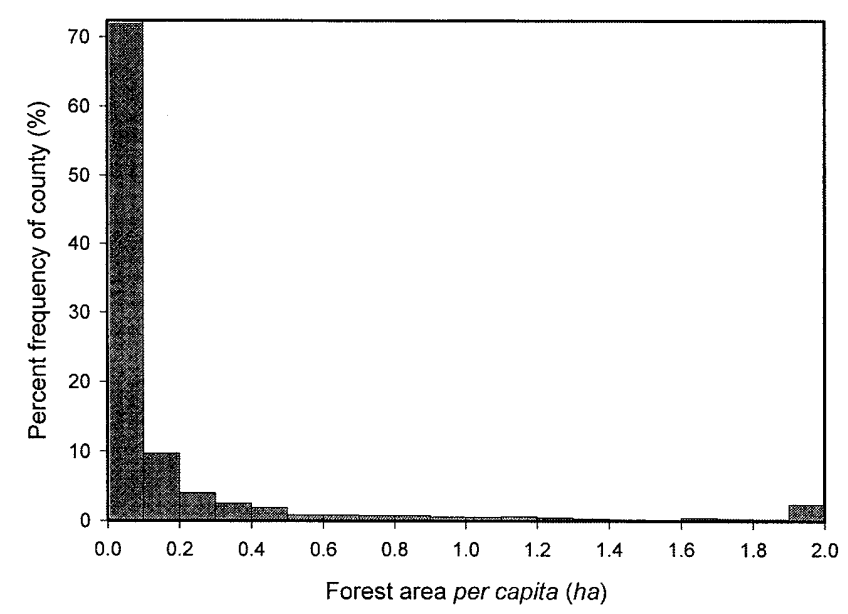

Fig. 3 Frequency distribution of forestland area per capita based on the county-level areas estimated from the SLCR database and China's population census data

the six regions (Table 2). This highlights the geographical differences in spatial distributions of forests and population across the six regions in China.

\section{North China :}

North China covers six provincial units (Beijing, Tianjin, Hebei, Shanxi, Shandong and Henan) and 510 counties, with a total land area of $691,774 \mathrm{~km}^{2}$ (7.3\% of China's territory). On the average, there is a $6.5 \%$ percentage forest cover in North China. Total forest area in North China accounts for 3.5\% of China's total forest area. Deciduous broadleaf and evergreen needleleaf plantations are the dominant forest types in this region. Approximately $73 \%$ of 510 counties in North China have less than 1\% forest cover (North in Fig.4). Only 15\% of 510 counties have a forest cover greater than the national average. Only $3 \%$ of these counties have a forest cover exceeding the global average of $34 \%$. The skewed frequency distribution of counties, as shown in Fig. 4, shows a very scarce and uneven distribution of forest resources in North China.

On the average, forest area per capita in North China is less than one-fifth of the national average of $0.11 \mathrm{ha}$, and is the lowest of all the regions in China (Table 2). Because of the low forest cover and high population density in North China, over $90 \%$ of 510 counties have a forestland area per capita lower than the national average, and only 4 counties have a forest area per capita exceeding the global average of 0.64 ha (North in Fig. 5).

\section{Northeast China:}

Northeast China includes Liaoning, Jilin and Heilongjiang provinces with 184 counties. Total land area in this region is $787,722 \mathrm{~km}^{2}$. Forests are mostly deciduous broadleaf and mixed natural forests, and this region has the nation's highest percentage forest cover at $41 \%$. Although the land area accounts for just $8.3 \%$ of China's territory, Northeast China has about $25 \%$ of China's forest area. $46 \%$ of 184 counties have abundant forest resources with a forest coverage higher than the national average of $13.48 \%$, and nearly $36 \%$ of all counties have a forest coverage exceeding the world average of $34 \%$. The frequency distribution of counties in Northeast China shows, while having the highest mean, the distribution is the most uneven of the six regions (Northeast in Fig. 4).

As one of the most important bases for timber production, Northeast China also has the highest forestland area per capita, about three times the national average (Table 2). Of 184 counties, there are 79 counties with a forestland area per capita higher than the national average (Northeast in Fig. 5). In particular, forestland area per capita in Xunhe, Mohe and Huma counties located in Heilongiiang province is as high as 16.87 ha, 19.55 ha and 67.15 ha, respectively.

\section{Central China :}

Central China comprises seven provinces (Shanghai, Jiangsu, Zhejiang, Anhui, Jiangxi, Hubei and Hunan) and 516 counties. Central China has a total land area of $915,427 \mathrm{~km}^{2}$, which is $9.7 \%$ of China's territory. Forestland in Central China contributes $17.8 \%$ of China's forest area, and covers $24.8 \%$ of regional land area. Main forest types in this region include evergreen needleleaf and mixed forests accounting for nearly $98 \%$ of regional forest area. $26 \%$ of the 516 counties have a forest coverage less than $1 \%$, and about $50 \%$ of the 516 counties have a forest coverage lower than the national average of $13.48 \%$. At the same time, $22 \%$ of 516 counties have adequate forest with a forest coverage exceeding the world average of 34\% (Central in Fig. 4). These results indicate the forestland distribution at county-level in Central China is relatively uneven.

Although the percentage forest cover in this region is the second highest in China, forestland area per capita is only 0.07 ha due to a high population level. There are 164 counties with a forestland area per capita higher than the national average of 0.11 ha, but forestland area per capita in almost all counties is 


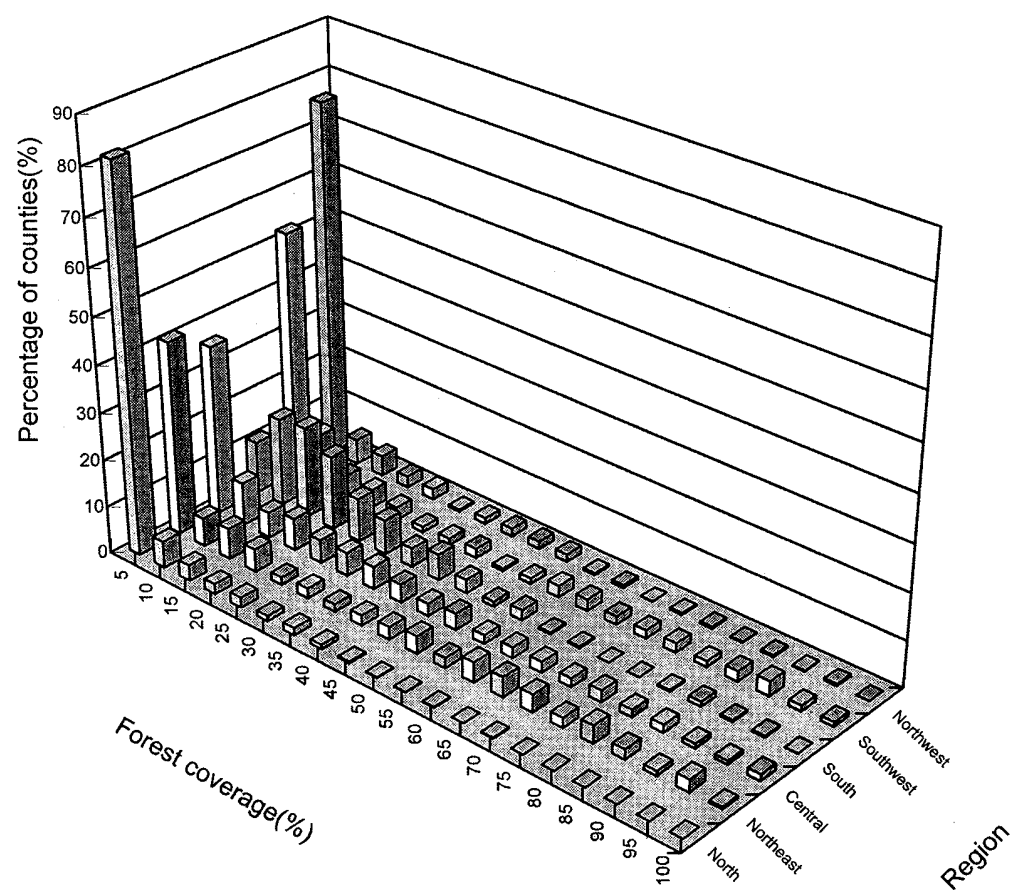

Fig. 4 Regional frequency distribution of forest coverage based on the countylevel areas estimated from the SLCR database

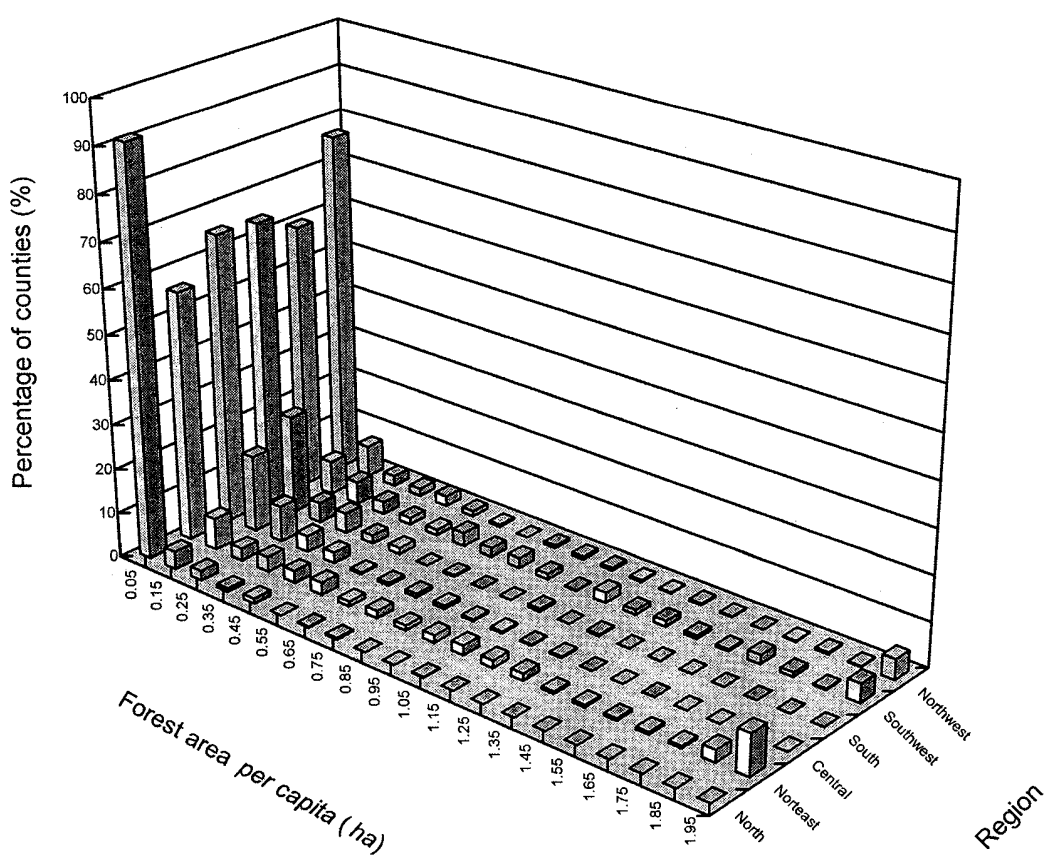

Fig. 5 Regional frequency distribution of forestland area per capita based on the countylevel areas estimated from the SLCR and China's population census data

lower than the world average (Central in Fig. 5).

\section{South China :}

South China has four provinces (Fujian, Guangdong, Guangxi and Hainan) with 273 counties. This region has a total land area of $569,926 \mathrm{~km}^{2}, 6 \%$ of China's territory. South China possesses $8.3 \%$ of China's forest, and, on the average, has a percentage forest cover of $18.6 \%$. Major forest types include evergreen needleleaf and mixed forests. Approximately $56 \%$ of the 273 counties have a percentage forest cover higher than 
$14 \%$, and only $3 \%$ of the 273 counties have a forest coverage lower than 1\% (South in Fig. 4). From Fig. 4, we also found the frequency distribution by county is less skewed than other regions.

There are two islands in Zhejiang lacking the population census data, so we calculated forestland area per capita for the 271 counties in South China. The frequency distribution of forestland area per capita in South China is very similar to that in Central China (South in Fig. 5). One significant difference between South and Central China, however, is that approximately $95 \%$ of the 271 counties in South China have a forestland area per capita higher than 0.01 ha. There are only 4 counties with a forestland area per capita exceeding the global average (Fig. 5).

\section{Southwest China :}

Southwest China has three provinces (Sichun, Guizhou and Yunnan) with 399 counties, and has a total land area of $1,125,194 \mathrm{~km}^{2}$, which is $11.9 \%$ of China's territory. Forestland in Southwest China covers $23.5 \%$ of its territory and accounts for $20.8 \%$ of China's forestland. The dominant vegetation types include evergreen needleleaf and mixed forests. $33 \%$ of the 399 counties only have a forest coverage of less than $1 \%$, while $24 \%$ of the 399 counties holds a percentage forest cover higher than the world average (Southwest in Fig. 4). Based on the frequency distribution by county in Fig. 4, it was clear that only a small proportion of 399 counties in this region have a percentage forest cover around the average value. That means forest distribution in Southwest China displays a clearly uneven pattern.

Forest coverage in Southwest China is slightly lower than in Central China, but forestland area per capita in Southwest China is more than double that in Central China, and 0.04ha higher than the national average. This is because the population density in Southwest is lower than that in Central China. Furthermore, there are as many as 83 counties with a forestland area per capita higher than the global average (Southwest in Fig. 5).

\section{Northwest China:}

Northwest China contains seven provinces (Inner Mongolia, Tibet, Shaanxi, Gansu, Qinghai, Niangxia and Xinjiang) with 493 counties. Northwest China has a total land area of $4,319,061 \mathrm{~km}^{2}$, about $44.6 \%$ of China's territory. Forests cover $5.8 \%$ of its land area, and account for $24.2 \%$ of China's forestland. Mixed forests, which occupy $62 \%$ of the total forest area, are the dominant forest types in this region. Approximately $67 \%$ of the 493 counties have a percentage forest cover lower than $1 \%$. Only $15 \%$ of 493 counties have a percentage forest cover equal to or higher than the national average (Northwest in Fig. 4). Basically, the pattern of frequency distribution by county in Northwest China was very similar to that in North China.

In Northwest China, since there is 1 county in Qinghai and 6 counties in Tibet without population data, we calculated forestland area per capita for 486 counties. Nearly $56 \%$ of the 486 counties have a forestland area per capita lower than 0.01 ha, but forest area per capita on the average is as high as 0.30 ha, which ranks second highest among the six regions. Because of sparse population in Inner Mongolia and Tibet, the forestland area per capita in several counties is as high as 253 ha (Northwest in Fig. 5). There are 103 counties with a forestland area per capita higher than the national average.

\section{DISCUSSION AND SUMMARY}

Analytical results on China's forest area estimates from the SLCR at county level have revealed the characteristics of China's forest resources at national and regional scales. According to the SLCR database, there is about 1.27 million $\mathrm{km}^{2}$ of forestland area in mainland China, representing a forest coverage of $13.48 \%$ of the total land area. The forest coverage in Northeast, Central, South, and Southwest China is above the national average, but less than $6.5 \%$ of land area in North and Northwest China is covered by forestland. Of 2,375 counties, there are 1,025 counties with a percentage forest cover less than $1 \%$, and $68 \%$ of these counties are located in North and Northwest China. North and Northwest China possesses 52\% of China's territory, but only $28 \%$ of China's forestland area. Moreover, there are only 400 mainland counties with a percentage forest cover exceeding the world average of $34 \%$. This result implies China has a low percentage forest cover compared with most countries, and the spatial distribution of forest resources is a very uneven at the regional scale.

Although China's forest resources have increased in area as well as stocking volume because of increased plantation establishment and control of timber harvesting in past decades, there are still serious problems with the existing forest resources related to the low forest coverage, uneven distribution, and dramatic decline in natural forest at a countylevel. These problems with forest resources have constrained China's capacity for timber production, biodiversity conservation, and environmental services. However, the ecological and economic demands on forest resources have been increasing through growth of economy and population, improvement of living standards, and raising of environmental awareness. Despite significant progress in China's forestry, there is still a big gap between China and most other countries with regard to forestland area, quality of forest resources, and forest productivity. In particular, because the population in forest regions has increased fivefold over the past 50 years, the natural forest has declined to $30 \%$ of the total forest area in China (ZhANG et al., 1999).

From the analytical results on forest area per capita, we have concluded that China's forest area per capita is only onefifth of the global average, and $43 \%$ of all counties are lower than 0.01 ha. In the intensively agricultural regions of North, Central, and South China, forest area per capita is much lower 
than the national average because of the concentration of population and the lack of abundant forest resources. Approximately $66 \%$ of Chinese live in the above three regions, but only $30 \%$ of China's forestland area is found there. Although the percentage forest cover in Northwest is the lowest in China, the region's forest area per capita is the second highest, as high as 0.30 ha.

On the other hand, there are about 263.3 million ha of land area for forestry in China, but forest occupies only $60.4 \%$ of total land area for forestry (State Forestry Administration, 2000). At the same time, China still has 46.9 million ha of land suitable for afforestation need to be afforested. The land suitable for afforestation almost equals to China's existing plantation area 46.7 million ha.

Regional scale analysis on county-level forest distribution can provide an important practical reference for China's future afforestation. Analysis at this scale provided a helpful perspective for China's forest resource management in the 21st century. First of all, enlarging the forest area is the most important task in North and Northwest China because of low forest coverage in these two regions. Of 1,003 counties in North and Northwest China, there are 702 counties with percentage forest cover less than $1 \%$, and only 53 counties with percentage forest cover higher than the world average. At the same time, the composition of forest types and tree species should be regulated to improve the ecological and economic functions of forest resources in North China. Secondly, forest resource management in Central, South and Southwest China should be concentrated on increasing forestland area, raising the quality of forest resources, and improving the composition of forest types and tree species. The average percentage forest cover in these regions is higher than the national average, but there are still 272 counties with percentage forest cover less than $1 \%$. Hence, it is crucial to utilize the large amount of land suitable for afforestation comprehensively. On the other hand, if monoculture forests replace natural mixed forest and naturally regenerated forest, biodiversity and perhaps other environmental services in Central and South China will be reduced. It is necessary to plant mixed forest and to conserve natural and secondary forests in these regions. Thirdly, the conclusion based on regional scale analyses suggests the function of timber supply in Northeast China should be enhanced to ease the timber supply shortage in China, by raising the productivity of forest.

Although China's forestland areas derived from the SLCR and from the NFRC93 are not completely consistent at the regional scale, county-level analysis of the distribution of forest resources using forest areas from the SLCR reveals the regional characteristics of China's forest resources. The discrepancies between the SLCR and NFRC93 forest area estimates can be explained by three main reasons. First, forest area in the NFRC93 is defined as land covered by trees with a percent canopy cover greater than $30 \%$, while the five forest types in IGBP are the land dominated by trees with a percentage canopy cover greater than $60 \%$. This factor may make the NFRC93 report greater forest areas in some provinces, compared to the SLCR. Secondly, the inherent inadequacy in spatial resolution of remote sensing data may also influence the accuracy of land cover classification, resulting in overestimation in some areas but underestimation in other areas. If a pixel is classified as forest, we allocate the entire area $\left(1 \mathrm{~km}^{2}\right)$ of that pixel to forest, with no land area for infrastructure (e.g. road, buildings, and idle land) or other land covers. In reality, the amount of non-forest area in each pixel assigned to forest may vary from $10-40 \%$. For instance, in the forest districts of Heilongjiang, Yunnan and Inner Mongolia, small scale cropland surrounded by large scale forests would be classified as $100 \%$ forest, and this may cause overestimated forest areas in those provinces. Inversely, the forest in North and South China mixed with croplands might be identified as cropland or cropland/forest mosaic, and this problem probably results in the underestimation of forest areas in these regions. Thirdly, although approximately 1.07 million $\mathrm{km}^{2}$ of the cropland/natural vegetation mosaic are distributed over mainland China, the quantitative proportions of forest and other vegetation types can not be easily determined within a 1$\mathrm{km}$ resolution pixel.

\section{ACKNOWLEDGEMENTS}

This work is supported by the Overseas Researchers Travel Fund of the Ministry of Education, Science, Sports and Culture, Japanese Government (for Yuejun Zheng), the USA NASA/EOS Interdisciplinary Science Program (for Xiangming $\mathrm{Xiao}$ ), and by the Chinese Academy of Sciences (for Zhongwei Guo). We thank Zhi-liang Zhu for providing the SLCR database.

\section{LITERATURE CITED}

Albers, H., Rozelle, S. and Guo, L., (1998): China's forest under economic reform: timber supplies, environmental protection, and rural resource access. Contemporary Economic Policy 16: 22-33

BELWARD, A. and Loveland, T., (1995): The IGBP-DIS 1km land cover project: remote sensing in action. Proceedings of 21st Annual Conference of the Remote Sensing Society: 1099-1106, UK, Southampton

CIESIN (Consortium for International Earth Science Information Network), (1998): The China Time Series Administrative Regions GIS Data: 1:1M, County Level, Prepared by CIESIN, the Chinese Academy of Surveying and Mapping, and China in Time and Space (University of Washington). http://sedac,ciesin.org/china /admin/bnd90/bnd90.html

Frolking, S., Xiao, X., Zhuang, Y., Salas, W. and C. Li, (1999): Agricultural land-use in China: A comparison of area estimates from ground-based census and satellite-borne remote sensing. Global Ecol. Biogeogr. Lett. 8: 401-416

HARKNESS, J., (1998): Recent trends in forestry and conservation of

\section{J. For. Plann. 7:69-78(2001)}


biodiversity in China. The China Quarterly 156: 911-934

HuAnG, J. and ScotT, R., (1995): Environmental stress and grain yields in China. American Journal of Agricultural Economics 77 853-864

Instimute of Geography, Chinese Academy of Science, State Planning Committee, State Economic Information Center and Institute of Statistics, State Statistical BuReau, (1994): National Economic Atlas of China, Oxford Univ. Press, Oxford, 314pp

Kong, F., Dai G., GaO, L. and HE, N., (1996): Forest environment resource accounting and economic compensation policy. Forestry Economics 1: 32-44

LI, C., (1998): Forest Resources and Management in China: Problems and Proposals. AMBIO 27: 578-579

LovelAND, T. and BeLwARE, A., (1997): The IGBP-DIS $1 \mathrm{~km}$ land cover data set, DISCover: first results. International Journal of Remote Sensing 18: 3289-3295

MinisTRY OF FoRESTRY, (1995): Afforestation and Forest Management Section and China Forestry Association (eds.). In Proceedings of the National Fuelwood Forest Symposium, 3 (In Chinese)

MinistRY OF FORESTRY, (1996a): Yearbook of Forestry. 23-58 (In Chinese)

Ministry of Forestry, (1996b): The National Census of Forest Resources (1989-1993). China's Forestry Press, Beijing, 255pp (In
Chinese)

Ministry of Forestry, (1996c): Contemporary China's Forest Resources (1949-1993). Report by the Division of Resource and Forestry Policy of Ministry of Forestry, China's Forestry Press, Beijing, 6-7 (In Chinese)

RICHARDSON, S., (1990): Forests and Forestry in China: Changing Patterns in Resource Development Washington DC, Island Press, 14

Running, S. Lovel, T. and Pierce, L., (1994): A average classification logic based on remote sensing for use in global biogeochemical models. AMBIO 23: 77-81

State Forestry Administration, (2000): Forrest Resources Statistics of China. 1-26 (In Chinese)

YANG, L., ZHU, Z., Lie, J. and Qui, Z., (1997): Seasonal land cover characteristics database of China for global change research. Proceedings of 1997 ASPRS/ACSM Annual Convention \& Exposition, ASPRS technical paper 2, Maryland: Bethesda: 82-84

ZhANG, P., ZHou, X. and WANG, F., (1999): Introduction to Natural Forest Conservation Program. China's Forestry Press, Beijing, $388 \mathrm{pp}$.

(Received 16 October 2000)

(Accepted 30 March 2001) 